
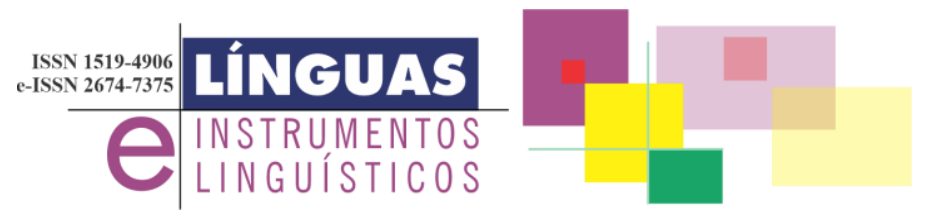

DOI: 10.20396/lil.v46i46.8661631

\title{
POR UMA REFLEXÃO SOBRE A "PROMESSA" NOS ESTUDOS PERFORMATIVOS
}

\section{FOR A REFLECTION ON THE "PROMISE" IN PERFORMING STUDIES}

\author{
Liliane Souza dos Anjos* \\ UNICAMP/FATEC
}

Resumo: Como ato de fala prototípico na tradição performativa, a promessa é analisada em diferentes estudos que promoveram leituras a respeito do legado de John L. Austin, como nos esforços de sistematização formal, em John Searle, ou mesmo a partir da dimensão do corpo, em Shoshana Felman. Este artigo revisita esse ato de fala em uma análise que busca explorar, com Jacques Derrida, a sua dimensão iterável, ao passo que reflete sobre a relação insustentável da promessa com o corpo e sobre sua subversão em relação ao político. Para isso, traz ao debate os trabalhos de Judith Butler e Joana Pinto, bem como a noção política de Jacques Rancière, em um diálogo que faz ver outros potenciais, falhas e infelicidades da promessa.

Palavras-chave: Performativo, Promessa, Atos de fala, Linguagem.

Abstract: As a prototypical speech act in the performative tradition, the promise is analyzed in different studies that promote readings of John L. Austin's legacy, for example, the formal systematization efforts in John Searle, or even from the body dimension in Shoshana Felman. This article turns to this speech act to explore its dimension iterable, from Jacques Derrida, as well as he reflects the unsustainable relationship of the promise with the body and with the politician. To this end, I summon the research of Judith Butler and Joana Pinto and the political notion of Jacques Rancière, brought to the text to show other potentials, mistakes, and infelicity of promise.

Keywords: Performative, Promise, Speech acts, Language. 


\section{Introdução}

How to do things with words seria atualmente um desses títulos de livros preferidos dos editores: promete a respeito de seu conteúdo sem que, para isso, precisemos abri-lo. O "how to do" aponta para o trabalho de um autor que parece anunciar a entrega de algo novo, daquilo que contrariaria toda uma tradição filosófica: o modo pelo qual agimos no mundo com as palavras. As palestras de Austin (1962) reunidas nessa importante obra, ainda que não tenham sido editadas pelo mestre inglês, deixam clara a infelicidade da promessa consignada em seu título, afinal, entre idas e vindas, reformulações e sutilezas, Austin não traça um caminho preciso para a compreensão do que seria "de fato" fazerdizer. Em contrapartida, o seu legado oferece subsídios para um vasto campo de estudos sobre os performativos, que, até hoje, não está isento de polêmicas, cumprindo, assim, muito além do que prometeu.

É no performativo instigante da promessa que concentro a reflexão presente nas próximas páginas. Como o principal exemplo de ato ilocucionário, uma etapa importante na argumentação de Austin surgida a partir do capítulo 8 de How to do things with words, a promessa é exaustivamente explorada por Searle (1969). Em um capítulo todo dedicado à estrutura de tais atos, Searle põe em foco a promessa por seu aspecto "formal e analisável", estabelecendo exclusões e abstrações em prol da elaboração de um conjunto de condições de realização do ilocucionário e uma posterior formulação de suas regras, condizente com um projeto para o qual as teorias da linguagem e da ação convergem.

Minha proposta para este artigo $^{1}$ considera, pois, a noção de promessa com o mesmo protagonismo, porém, leva em conta aquilo que Searle nega, adentrando em pontos de dissonância da teoria dos performativos, a partir de autores incontornáveis como Derrida, Felman e Butler, em posições teóricas marcadamente distintas daquele. Deixo claro, contudo, que não retomo Searle como herdeiro de Austin ${ }^{2}$. O gesto de escolhê-lo como ponto de partida justifica-se por suas reflexões particulares em torno da promessa, sobre as quais produzo aqui uma leitura de cunho negativo, evidenciando as sobras de sua reflexão. 
Nessa perspectiva, proponho compreender as condições do performativo pelo que ele se recusa a reconhecer. Ou seja, procuro pela promessa para além do aspecto sistematizável de suas formulações: uma promessa perdida na instância ambivalente do corpo, ou na insurreição do político. Tais abordagens, ao passo que são irreconciliáveis à de Searle, tocam no que a promessa tem de particular e no exercício de questões importantes para os estudos do performativo, como por exemplo, a referencialidade e a significação. Meu objetivo é, portanto, revisitar tais “excluíveis” em Searle e reintegrá-los à promessa a partir de uma posição voltada aos pressupostos do pensamento de Jacques Derrida, demarcando as implicações de tal abordagem para o estudo da promessa em sua especificidade.

Para tais propósitos, divido esse artigo em três partes, além desta. A primeira procura situar teoricamente os estudos da promessa em Searle e seu papel na tradição dos estudos de atos de fala, em contraponto com a perspectiva de Derrida. Em seguida, busco compreender a promessa situada no corpo, com o suporte teórico de Judith Butler e Shoshana Felman. Na terceira parte, ponho em foco a promessa pelo viés político, convocando, para tanto, a noção de política do filósofo Jacques Rancière e a reflexão em torno do político no performativo, presente em Butler, a partir de Excitable Speech.

\section{A promessa em Searle e suas complicações}

O próprio Searle (2010) falará de seu lugar na tradição dos estudos de atos de fala. Segundo ele, no que diz respeito aos fenômenos sociais no âmbito desses estudos, as pesquisas das décadas de 1950 e 1960 dividiram-se em duas grandes tendências: a primeira, de tradição subjetivista, conduzida por Paul Grice (1957, 1969), ofereceria destaque à intencionalidade individual, confinando o significado aos atos individuais, sem quaisquer indícios de convenções, regras ou práticas sociais; a segunda, que estaria ligada a Austin ${ }^{3}$ (1962) e Searle (1969, 1983), de tradição objetivista social ou wittgensteiniana, atentaria para as instituições sociais na realização dos atos de fala, tratando o significado como resultado das práticas sociais e não só como produtos de uma subjetividade solipsista. 
Muito embora Searle tenha se situado lado a lado com Austin, é notável o fato de que a sua hipótese de que falar uma língua é adotar uma forma de comportamento - o que, por sua vez, forneceria regras constitutivas, susceptíveis de serem estudadas a partir de seus traços formais - vai de encontro às críticas austinianas ${ }^{4}$ a um atomismo e positivismo lógico da filosofia da linguagem. Autores como Claudiana Alencar (2006, p. 40) sugerem, inclusive, um Searle capaz de apresentar "sua própria concepção de ato de fala, nos moldes de tradição clássica da filosofia analítica, ao inscrever em seu discurso o vocabulário próprio do discurso dos formalistas".

É assim que em Speech Acts: An Essay in the Philosophy of Language (1969) (doravante, SA), Searle busca o aspecto analisável dos atos ilocucionários, situando, a partir de Austin, a promessa como seu exemplo mais emblemático. Devemos ter em mente, contudo, que é essa tendência descritivista que tornará possível a delimitação entre os conceitos de atos de fala e ilocucionário em Searle, distinção que não esteve presente em Austin. A esse respeito, Ottoni (2002, p. 125) comenta:

Em muitos casos, a delimitação desses
conceitos, só será possível através de uma
linguística descritiva, lingüística esta que não
incorporou a quebra de barreiras filosóficas e
lingüísticas proporcionadas por Austin. Daí as
diversas interpretações que não conseguem
delimitar e nem distinguir o conceito de
performativo dos outros conceitos
relacionados: o ilocucionário e ato de fala.

Pela visão performativa da linguagem, nomenclatura utilizada por Ottoni $(1998$, 2002) para o legado de Austin, não existiriam barreiras entre a filosofia e a linguística. Ao conceber que a linguagem não se aparta do humano, Austin permanece distante do entendimento searleano de que uso e significação seriam distintos. Ora, a significação se filiaria à intenção do falante, numa entidade mental, ao passo que a prática linguística seria, enquanto uma ferramenta de análise em si 
mesma, uma noção vaga que não poderia influenciar no sentido da sentença.

Sendo o significado associado à intenção, Searle anuncia a diferença entre a intenção de representar determinados estados de coisas por meio de certas modalidades ilocucionárias e a intenção de comunicar essas representações a um ouvinte. A intenção de representar diz respeito à maneira de determinar a força e o conteúdo do ato de fala; já a de comunicar refere-se à intenção de causar no ouvinte o conhecimento dessa força e desse conteúdo. No âmbito da promessa, por exemplo, se alguém promete ir até outrem em uma data específica, seria preciso distinguir entre a intenção de se comprometer a ir àquela pessoa naquela data e a intenção de comunicar a ela esse compromisso.

$\mathrm{Na}$ concepção searleana, os atos ilocucionários seriam, ao mesmo tempo, a unidade básica do significado pretendido pelo falante e a unidade básica de comunicação, fazendo-se necessário distinguir entre essas as duas naturezas de intenção mencionadas anteriormente. A intencionalidade para Searle se relaciona, por sua vez, às condições de satisfação, que diriam da qualidade para que a fala seja inteligível, da obviedade do ato, do desejo do ouvinte de que aquele ato seja realizado, ou ainda, das condições de sinceridade. No que diz respeito à promessa, por ser reservada à categoria dos atos ilocucionários de comprometimento (comissivos), ela estaria associada a uma característica adicional: a autorreferencialidade. Vejamos, pelo exemplo do autor, como isso funciona:

Se prometo vir à sua casa na quarta-feira à noite e me esqueço inteiramente da promessa, mas na quarta-feira decido ir à sua casa para lhe pedir dinheiro emprestado, então, em certo sentido, ao chegar à sua casa, ainda não cumpri a promessa, porque a promessa não foi uma razão para eu fazer o que eu fiz. É claro que não quebrei a promessa, mas tampouco a mantive. Por que não? Porque a promessa promete não somente que certa ação ocorrerá, mas que ocorrerá como cumprimento da promessa (SEARLE, 2010, p. 240). 
Tais considerações levam a compreender que as condições de satisfação da promessa são causalmente autorreferenciais, visto que não se resumem ao fato de ocorrer o ato, mas que ele ocorra por sua causa. São essas as intenções de significação, enquanto que as intenções de comunicação residem no fato de o ouvinte reconhecer a enunciação e reconhecer que ela tem as condições de satisfação que o falante pretende que tenha. Em outras palavras, o sucesso da comunicação consistiria no reconhecimento das intenções de significação do falante.

$\mathrm{O}$ ato de prometer, contudo, não estaria garantido somente pela intencionalidade do falante e por sua percepção pelo ouvinte. Searle acrescenta que a promessa só é entendida como tal porque faz parte de uma prática linguística geral. Falar "eu prometo" seria, então, realizar uma regra constitutiva e subjacente segundo a qual fazer uma promessa, ou seja, executar um ato de fala, equivaleria a comprometer-se com a obrigação de fazer alguma coisa, normalmente para o benefício do ouvinte $^{5}$. Regra constitutiva, afinal, como sabemos, a noção atemporal do ato de fala em Searle postula que o comportamento intencional é regido por regras passíveis de sistematização.

Seguindo tal lógica, Searle irá propor as condições para o cumprimento desse ato a partir de uma sentença-chave traduzida assim: "Dado que um falante $\mathrm{F}$ profere uma sentença $\mathrm{S}$ na presença de um ouvinte $\mathrm{O}$, então, ao emitir literalmente o enunciado $\mathrm{E}, \mathrm{F}$, sinceramente e de maneira indefectível, promete que p a $\mathrm{O}$, se e somente se [...]" (SEARLE, 1969, p. 57 - grifos meus) determinadas condições forem satisfeitas. $\mathrm{O}$ destaque que dou para o caráter literal do enunciado aponta para um projeto no qual o locutor estaria falando tudo o que se pretenderia ser dito. Daí a importância da condição de sinceridade que expressaria o estado psicológico do falante. Prometer seria, então, a expressão exata da intenção de fazer algo, uma vez que, para Searle, é sempre possível que o locutor diga exatamente o que ele quis dizer ${ }^{6}$. Isso nos leva à questão da indefectibilidade do enunciado da promessa. Em um contexto idealizado, o locutor sempre estaria diante de uma transparência pela qual sua ideia seria expressa diretamente pelo enunciado, apartando a sentença de toda imprevisibilidade. 
A promessa no projeto searleano, portanto, não poderia ser compreendida no concreto da prática linguística ${ }^{7}$. Ao supor que, em uma situação ideal, o locutor sempre falaria aquilo que teria a intenção de dizer, Searle privilegia a noção de literalidade, e consequentemente, a ideia do dizer em detrimento do fazer, apagando uma possível consideração do caráter performativo da promessa. Resta-me, nesse ponto, compreender no contexto do projeto de SA, o lugar da comunicação e sua relação com a força do ilocucionário. Para isso, procuro entender como Searle persegue uma caracterização pormenorizada da força do ilocucionário, assim como uma notória distinção entre a noção de força ilocucionária e do próprio ato ilocucionário.

\subsection{Força e comunicação na promessa}

Um mesmo enunciado pode constituir o desempenho de vários atos ilocucionários diferentes, diz Searle (1969). Nessa distinção, estão implicados aspectos como o propósito do ato, as posições dos interlocutores, o grau de compromisso assumido, a diferença no conteúdo proposicional, a singularidade no modo como a proposição se relaciona com os interesses de cada interlocutor, os distintos estados psicológicos expressos e, finalmente, as formas particulares nas quais um enunciado se relaciona com o resto da conversa.

Vejamos o exemplo, dado pelo autor, na seguinte situação: em uma festa em que a esposa diz "está realmente muito tarde", tal enunciado pode configurar-se como uma declaração, ou para seu interlocutor, pode transformar-se em uma objeção, ou ainda, para o marido, o mesmo enunciado pode ser intencionado como um pedido ou sugestão ("Vamos para casa"). O fato é que o exemplo abre espaço para que se marque a sempre possível não coincidência entre a força e o ato ilocucionário. Um hiato entre as situações idealizada e concreta, a partir da força do ilocucionário centrada no módulo psicológico do falante. É a partir do que está presente no psicológico do falante e do ouvinte que se têm vários atos ilocucionários para um mesmo enunciado.

A questão de comunicar estará sempre associada à intenção de comunicar de que falei anteriormente: a intenção de proporcionar ao 
ouvinte o conhecimento da força e do conteúdo da comunicação. É a comunicação, aliás, o ponto que Raoul Moati (2009) irá considerar como convergente entre Searle e Derrida (1991b), este incontornável filósofo o qual oportunamente convoco a fim de nos apresentar outra perspectiva para o performativo promessa.

Começo, então, tomando o exemplo acima pela perspectiva derridiana. As motivações para as múltiplas possibilidades na comunicação do enunciado "está realmente muito tarde" voltar-se-iam para a possibilidade estrutural de um enunciado ser repetido independentemente da uma intenção determinada, pondo em xeque a intencionalidade diretiva de Searle. Ainda segundo Moati (2009), as convenções que, para Searle, garantiriam a inteligibilidade intencional da sentença, para Derrida, seriam a fonte da subversão do enunciado, não fazendo sentido, então, a distinção entre uso ordinário e parasitário da linguagem. Outro ponto de disputa entre os autores.

Em "Assinatura Acontecimento Contexto", Derrida (1991b) considera que entre o enunciado e seu contexto de produção não existe uma ligação que não possa ser quebrada. Todo enunciado performativo é iterável, por conseguinte, a promessa também o é. Ou seja, tem a capacidade de ser repetível, de modo estruturalmente acidental. Pela différance ${ }^{8}$, cujo predicado fundamental é a ausência. Tem-se, nesse caso, a garantia estrutural de legibilidade do enunciado, a despeito da presença dos interlocutores ou de uma intenção definida. Derrida, então, articula a relação entre marca e iterabilidade como é possível ver no excerto a seguir:

Toda a escrita deve, pois, para ser o que ela é, poder funcionar na ausência radical de todo destinatário empiricamente determinado em geral. E essa ausência não é uma modificação contínua da presença, é uma ruptura da presença, a "morte" ou a possibilidade da "morte" do destinatário inscrita na estrutura da marca (é neste ponto, noto de passagem, que o valor ou o "efeito" de transcendentalidade se liga necessariamente à possibilidade da escrita 
e da "morte" assim analisadas") (DERRIDA, 1991b, p. 19-20).

"Para ser o que é" é preciso que o enunciado funcione em uma ausência do destinatário, afirma Derrida numa formulação, exatamente oposta a uma citação de Searle, que aqui traduzo da seguinte maneira:

Os conceitos de jogo, cadeira ou promessa não têm condições absolutamente necessárias e suficientes, tal que, a menos que estejam satisfeitas, algo não pode ser um jogo, uma cadeira, ou uma promessa, e, dado que estejam satisfeitas em um caso particular, esse não pode ser outra coisa senão um jogo, uma cadeira ou uma promessa (SEARLE, 1969, p. $55)$.

Se, por um lado, o autor de SA defende que para uma promessa (ou um jogo, ou uma cadeira) se configurar como tal é necessário que determinadas condições sejam satisfeitas, aqui Derrida aponta para um aspecto não levado em conta por Searle, mas que a própria noção de promessa esconde: "a destruição de todo o contexto como protocolo de código" (DERRIDA, 1991b, p. 20) contido no compromisso de um eu prometo. Em outras palavras, prometer implica categorias de ausência que ultrapassam regras gerais, uma vez que a promessa possui a capacidade de comprometer-se a uma ação na ausência do interlocutor e na projeção de um futuro que estaria fora de controle.

\subsection{A ausência na promessa}

Mencionei, a partir de Searle, as condições de satisfação para o sucesso do ato de fala prometer, no entanto, acredito que um exercício de compreensão específico do tipo de condição proposicional nos ajudará no entendimento do lugar da ausência nesse ato de fala: Ao expressar que p, F predica um ato futuro A de $F^{9}$ (SEARLE, 1969, p. 57). 
No escopo do dispositivo formalizado do ato de prometer, exemplificado acima, depreendem-se duas características: a qualificativa (ou predicativa) do falante e a do futuro de sua ação. Searle põe em relevo a indicação da predicação como sobre quem enuncia e não sobre o ouvinte - para ele, não se pode prometer que alguém fará alguma coisa - e sobre o objeto - pode-se prometer não fazer algo, fazer algumas coisas repetidamente ou sequencialmente, prometer ser ou permanecer em determinada condição. A promessa realizada pelo falante pode ainda, em sua ausência empírica, configurar-se como tal, sobretudo no que Searle menciona da possibilidade de prometer fazer coisas de modo repetido ou sequencial. Vejamos como ele formula essa questão:

\begin{abstract}
A noção de ato, tal como a interpreto para os presentes propósitos, inclui abster-se de realizar certos atos, realizar séries de atos, posso prometer fazer algo repetida ou consecutivamente, e posso prometer estar e permanecer em determinado estado ou situação. [...] Estritamente falando, posto que expressões e não atos são predicados de objetos, esta condição deveria ser formulada como se segue: Ao expressar que $\mathrm{p}, \mathrm{F}$ predica uma expressão de $\mathrm{F}$, cujo significado é tal que se a expressão é verdadeira do objeto, é verdadeiro que o objeto realizará um ato futuro A (SEARLE, 1969, p. 57-58).
\end{abstract}

Do ponto de vista da temporalidade da ação de tal ato ilocucionário, a possibilidade de dispensa da presença parece-me notável, o que está relacionado ao caráter iterável do performativo, e isso tanto em Searle, quanto em Derrida. Explico-me: como mencionei, a comunicação é o ponto em comum entre esses autores, mas a perspectiva da comunicação tem nuances diferentes para cada um. Conforme sabemos por Ottoni (1998, p. 55) "a performatividade, segundo Derrida, é um ato de comunicação ${ }^{10}$; para Searle, o ato de comunicação é uma das várias possibilidades do performativo, do ato de fala”. Assim, a 
iterabilidade do performativo se distingue em ambos. Enquanto Derrida enxerga a iteração como um fundamento para a constituição da performatividade enquanto comunicação que é; para Searle, "a iteração é uma pressuposição necessária para as formas através das quais a intencionalidade se configura" (OTTONI, 1998, p. 57)

Diante de uma ação que se realizará no futuro, a promessa, em sua iterabilidade, encerra uma não-presença. Ela projeta uma ação futura, torna a presença do autor sempre atualizada, porque marca e mantém, para além do momento da enunciação, uma não-presença. $\mathrm{O}$ que remete, de imediato, à noção de assinatura na análise derridiana:

Por definição, uma assinatura escrita implica a
não-presença atual ou empírica do signatário.
Mas, dir-se-ia, marca também e retém seu ter-
sido presente num agora passado, que
permanecerá um agora futuro, logo um agora
em geral, na forma transcendental da
permanência. Essa permanência geral está de
algum modo inscrita, presa na pontualidade
presente, sempre evidente e sempre singular,
da forma da assinatura (DERRIDA, 1991b, p.
35).

À condição da impossibilidade de uma pureza rigorosa, os efeitos de assinatura estão presentes no dizer a todo o momento, em um funcionamento que ocorre devido à característica iterável da própria assinatura. Ou seja, dada à capacidade de a assinatura apartar-se da intenção de sua produção e da presença física do falante $(\mathrm{F})$, fica marcada a sua capacidade de ultrapassar a temporalidade do momento da fala ou da escrita. $\mathrm{O}$ que nos leva à compreensão de ato fundado na noção de rito, pelo qual a iterabilidade ${ }^{11}$ estrutural da linguagem é traço decisivo, implicando identidade e alteridade simultaneamente.

Nesse ponto da discussão, a leitura de Derrida por Judith Butler intervém fortemente. Em Excitable Speech, a autora, ao tratar dos atos ilocucionários, dirá que tal ato deve incluir uma compreensão de como determinadas convenções são invocadas no momento da sua própria enunciação. Butler, então, retoma Austin nos lembrando que a categoria 
tem um funcionamento cerimonial, ou ritualístico, sendo enunciado repetível, se mantém em um escopo não restrito ao momento da fala. Nesse ponto, ela inclui a questão da historicidade que se concentra no ato, fazendo romper as barreiras do próprio contexto de realização: "nunca é apenas um único momento. [...] ela (a historicidade) excede em direções passadas e futuras, um efeito de invocações prévias e futuras que constituem e escapam ao enunciado" (BUTLER, 1997, p. 3).

Ao evocar condições históricas e rituais, o performativo opera uma realidade, instigando um futuro que não se submete a regras. Tais argumentos de Derrida põem em xeque o efeito legitimador da presença subjetiva a partir do momento em que a fala se transpõe para a escrita, a partir da lógica da iterabilidade, mas, ao mesmo tempo, deixa em aberto uma leitura de caráter desconstrutor para a questão da fala. A esse respeito, a filósofa e psicanalista Shoshana Felman (1980) retoma uma leitura desconstrutivista dos atos de fala, capaz de levantar tal questão reintegrando o ilocucionário ao corpo, sem que para isso defenda um sujeito soberano. Aqui, caminhamos à compreensão de uma promessa como ato de fala a partir do status do corpo na linguagem.

\section{Corpo, promessa, escândalo}

Como compreender a promessa a partir de uma visão performativa da linguagem? A noção trazida por Ottoni sobre o legado austiniano é bastante oportuna para os objetivos deste artigo. Dessa forma, sabemos pelo autor que Austin introduz:

[...] através da visão performativa, uma relação insolúvel entre sujeito e objeto. O sujeito e objeto, para Austin, o eu e o não-eu, se fundem, passando ambos a fazer parte da significação. Ou seja, na visão performativa, o sujeito falante empírico se constitui como sujeito através do uptake, que, sendo o lugar do deslocamento da intencionalidade, subverte o papel centralizador e consciente deste sujeito (OTTONI, 1998, p. 13). 
Na busca pela visão performativa da promessa, é incontornável a noção de uptake, expressão traduzida frequentemente como apreensão. Ottoni nos dirá que essa é a mais importante maneira de distinguir o ato ilocucionário do perlocucionário. Trata-se de relacionar os interlocutores, relação pela qual é possível notar o quanto a referência estaria mais diretamente ligada ao momento da enunciação. Em outras palavras, o uptake refere-se ao reconhecimento entre falante e ouvinte de que algo estaria apreendido/assegurado. Uma espécie de "check" de que o objetivo do ato ilocucionário, através de sua força, foi realizado.

Nota-se, por essa noção, que, sozinho, o sujeito não teria mais o domínio da significação, como em Searle. O "controle" do significado estaria nas mãos dos interlocutores, constituindo-se no momento da própria enunciação. Por ser o lugar em que há o "desmantelamento da intenção, o caminho próprio da desconstrução" (OTTONI, 1998, p. 82), o uptake marcaria uma subversão dando lugar à assimetria entre sentido e referência.

Nesse momento de sua discussão, Ottoni faz menção a Shoshana Felman e a seu modo de compreender Austin. Ambos estão de acordo com o fato de que é da assimetria que provém o pensamento do filósofo inglês, pelo qual se torna incompatível a correspondência exata entre enunciado e sentido, rompendo com a intenção originária dos interlocutores.

Uma visão performativa da linguagem abre possibilidades para a quebra de fronteiras entre corpo e linguagem. Apesar da complexidade das interpretações em torno do legado austiniano, um conjunto importante de seus estudos atentou para alguns precedentes em Austin ${ }^{12}$ pelos quais é possível pensar a imbricação entre o sujeito do ato de fala, $\mathrm{o}$ ato físico, bem como as suas consequências. É sobre isso que nos fala Joana P. Pinto (2009, p. 121). A autora comenta que foram tais precedentes que abriram "espaço para uma aproximação dos estudos de atos de fala com os estudos do corpo".

Um dos marcos teóricos da abordagem do corpo nos estudos do performativo, conforme demonstra a autora, é a publicação do livro $L e$ scandale du corps parlant: Don Juan avec Austin ou la seduction en deux langues de Felman (1980), de quem falou Ottoni: um trabalho que 
reinterpreta Austin com influência notória das ideias de Derrida, bem como articulações com a psicanálise lacaniana. Nesta obra, encontro um importante suporte teórico para a compreensão da promessa na instância do corpo.

No posfácio da tradução inglesa, Judith Butler menciona o modo brilhante pelo qual Felman demonstrou que não há ato de fala sem o corpo e, ao mesmo tempo, como o corpo limita o papel da intenção no ato de fala ${ }^{13}$ (BUTLER, 2003, p. 113). Para o que pretendo neste artigo, essa obra é de extrema importância, uma vez que, ao ler Austin em conjunto com a obra literária Don Juan de Molière, Felman lança luz sobre as falhas do performativo promessa pari passu com a teorização do ato de fala a partir do corpo.

A promessa, para Felman (1980), não é um modo de representar uma intenção do falante, nem momentânea, nem continuamente ao longo do tempo. Ela se opõe a um ilocucionário transparente sustentado por uma consciência pura, o eu nos moldes searleanos. Para a filósofa, a promessa como ato, e não como constatação, "é um signo de uma contradição fundamental que é, precisamente, a contradição do humano"14, o que diz da insuficiência de uma investigação estritamente linguística e formal.

Em sua análise de Don Juan, Felman vai demonstrar como a promessa pôde funcionar a serviço da sedução do personagem, uma vez que ela é feita e quebrada diversas vezes, sem representar uma verdade interior capaz de durar, não assegurando, assim, uma ação futura. Numa demonstração clara da diferença entre uma visão constativa e performativa da linguagem, Felman compreende que o personagem Don Juan compartilha de uma visão performativa pela qual a linguagem não é:

[...] em nenhum caso saber ou conhecer, mas fazer: agir sobre o interlocutor, modificar a situação e suas relações de força. Performativo e não informativo, a linguagem, para ele, é um campo de gozo e não de conhecimento; enquanto tal, não é suscetível de verdade ou de falsidade, mas, antes e exatamente, de 
felicidade ou infelicidade (felicity/infelicity), de sucesso ou de fracasso (FELMAN, 1980, 34). ${ }^{15}$

A promessa, em Felman, trata-se de um ato que se refere ao próprio fazer e objetiva alterar algo na situação de ato de fala em que se realiza. Como destaca Butler, a promessa faz algo diferente do que promete porque está atada ao corpo do falante. Sendo o corpo uma pré-condição do discurso, a promessa é uma ação que se presentifica no corpo e é um prenúncio do que o corpo fará e, já que o corpo não pode ser esgotado, conhecido ou representado pela promessa, ela é impossível de ser mantida. Em suas palavras: "É sempre uma questão de saber se a promessa pode ser mantida, se as suas 'intenções' serão descarriladas ao longo do caminho" (BUTLER, 2003, p. 120).

Como está claro, a leitura de Butler sobre o trabalho de Felman anuncia o impacto que teve a publicação dessa obra, impulsionando movimentos interdisciplinares para a compreensão dos estudos sobre o performativo. O trabalho de Judith Butler, por sua vez, constitui o que Pinto (2009) irá chamar de o terceiro marco para os estudos que relacionam a linguagem e o corpo. Seus estudos sobre o corpo levantam questões de cunho político que muito me interessam na compreensão da promessa. No escopo deste trabalho, Butler também intervém naquilo que me faz perguntar pela possibilidade de compreensão da promessa enquanto uma questão política. Assim, interrogo os limites dos estudos do performativo na compreensão do modo como o Estado se relaciona com seus cidadãos. Essas inquietações nortearão a próxima seção.

\section{Promessa e política: encontro não evidente}

A promessa enquanto categoria relacionada ao fazer político não pode passar ilesa em sua suposta transparência. Para dar conta de uma visão performativa da promessa, uma que tem espaço no corpo, e que se dá no momento de seu proferimento, é preciso falar de uma promessa com dimensões sociais, cujas consequências não são jamais evidentes. E é aí que entra o político. 
Tal questão está marcadamente presente em Excitable Speech, texto para o qual retorno a fim de pontuar a relação do político com a teoria do performativo. Butler faz questão de enunciar o funcionamento do performativo no exercício do discurso político. Para ela, compreender a performatividade como uma ação que se renova, ou seja, sem origem ou fim claros, é ter em mente que o ato de fala não é restrito nem ao falante específico, nem ao seu contexto de origem, abrindo-se em sua dimensão social. Assim, a performatividade tem sua própria temporalidade histórica, na qual permanece já habilitada precisamente pelos seus contextos e, ao mesmo tempo, pelo rompimento com eles.

Esse caráter ritualístico e, simultaneamente, subversivo, do performativo evidencia resistência e insurgência política. Ou seja, um e outro são gerados em parte pelos poderes a que se opõem, e como, para Butler, a lógica da iterabilidade deve ser encarada como lógica social, a performatividade em sua repetição engendra a sempre possível mudança no social. Mas, como especificar a promessa no âmbito dessa discussão?

Um caminho possível seria abrir mão de um aspecto mais estrito e evidente da questão, afastando-se de um tratamento da promessa como um proferimento cujo enunciador é uma figura pública, por exemplo. Focalizo, então, o funcionamento de todo ato de fala enquanto ato de fala político, no sentido de oferecer novas possibilidades no interior da linguagem. Possibilidades as quais Butler faz menção para tratar da sempre frágil fronteira de legitimidades dos atos de fala: "a ressignificação do enunciado requer a abertura de novos contextos, falando de modos que nunca foram legitimados e, portanto, produzindo legitimação em formas novas e futuras" (BUTLER, 1997, p. 41).

Desse entendimento, com efeito, posso levar em conta a noção de política de Jacques Rancière. Para o filósofo, a política não é atributo imanente de coisa alguma, não tendo objetos ou questões que lhe sejam próprios. Antes, tem como princípio uma igualdade cujo estatuto, destaca ele, deve ser especificado. Um objeto, um lugar, uma ação, uma "palavra-ação", acrescentaria, pode tomar a forma do político desde que inscreva a verificação da igualdade, sob a forma de um litígio. Eis o 
caráter subversivo do político em sua forma mais contundente, como é possível ver a seguir:

A atividade política é sempre um modo de manifestação que desfaz as partilhas sensíveis da ordem policial ao atualizar uma pressuposição que lhe é heterogênea por princípio, a de uma parte dos sem-parte que manifesta ela mesma, em última instância, a pura contingência da ordem, a igualdade de qualquer ser falante com outro ser falante qualquer. Existe política quando existe um lugar e formas para o encontro entre dois processos heterogêneos (RANCIÈRE, 2018, p. 44).

Sendo assunto dos sujeitos, a política se faz nos modos de subjetivação pelos quais identidades que seriam definidas como naturais são realocadas em instâncias de litígio. É “a contagem dos que não contam”, "a diferença entre a distribuição desigualitária dos corpos sociais e a igualdade dos seres falantes" (RANCIÈRE, 2018, p. 52). Uma subjetivação política recorta o campo da experiência, deslinda e refaz modos de ser, fazer e dizer que definiriam previamente a organização da comunidade.

Por essa razão o investimento para além da figura do personagem político prometedor é mais produtiva. Uma vez que se rompe com a evidência de um lugar próprio reservado à promessa, rompe-se um circuito de manutenção de uma ordem que Rancière (2018, p. 43) chamará de policial: "uma ordem do visível e do dizível que faz com que essa atividade seja visível e outra não o seja, que essa palavra seja entendida como discurso e outra não". Assim, posso falar de uma promessa que se torna política à medida que reconfigura as relações, arranca o espaço da naturalidade e celebra experiências singulares capazes de fazer contar aqueles que não são contados.

Sob esse ponto de vista mais amplo, a relação da promessa com a política pode ser pensada, conforme Butler, a partir de uma conciliação com a noção althusseriana de interpelação. Ora, pela tese central do 
filósofo franco-argelino, sabemos que "a ideologia interpela os indivíduos como sujeitos" (ALTHUSSER, 1996, p. 131). Uma afirmação que vai de encontro a uma possível intenção diretiva do performativo. Quando de seu trabalho com a promessa, o próprio Austin refuta formas de psicologismo, identificando que mesmo uma intenção de não realizar uma promessa seria incapaz de privá-la de seu status de promessa. Nas palavras de Ottoni (1998), o sujeito falante se constitui como tal através da apreensão (uptake), subvertendo a visão de uma consciência onipotente.

Butler, então, considera que a linguagem que traz o sujeito à existência está presente em Austin e em Althusser: "De fato, a interpelação que precede e forma o sujeito em Althusser parece constituir a condição prévia dos atos de fala centrados no sujeito que habita o domínio de análise de Austin” (BUTLER, 1997, p. 24). Fica claro, mais uma vez, que o centro do debate está na força do ilocucionário e no seu caráter iterável. Um ligado ao outro, uma vez que, no ato de fala, força e significado são separáveis e a força ilocucionária está assegurada por convenção.

Se por um lado, Austin determinou a exposição ao fracasso de todo ato convencional e, por outro, Derrida postulou que todo ato corre o risco de falhar dada a arbitrariedade do signo, a promessa enquanto performativo, político, é puro fracasso. O fracasso da polícia dos sentidos, dos contextos determinados e da intenção diretiva. É desse caráter subversivo que falei anteriormente: a promessa excede a autonomia de contextos de onde emerge, sejam eles oficiais ou não, ao mesmo tempo em que reflete condições sociais anteriores, produzindo uma série de efeitos na sociedade.

Não é, portanto, um ato singular de um falante F, figura pública ou não. É uma forma pela qual o sujeito é interpelado para ser no social, em diferentes espaços sociais. Se, por exemplo - e neste ponto é impossível não tomar como exemplo minha pesquisa de doutorado -, o Estado promete paz para a favela, através de intervenções militares, ele não deixa de operar um ato capaz de formar esse sujeito favelado, marcando, pela força, seus corpos. Na configuração dessa experiência, "no nó entre as partilhas da ordem policial" (e aqui policial ${ }^{16}$ está aberto 
a outras significações), a política intervém propondo novas zonas de divisão de sentidos. Quem promete o que e para quem? A pergunta implica um deslocamento na ordem da divisão, propondo um olhar para a multiplicidade de relações, dando a ver existências que são ao mesmo tempo inexistências (RANCIÈRE, 2018, p. 57).

Com isso, para retomar meu exemplo, a promessa de paz falha. E falha em seu próprio funcionamento, por se valer de objetos que não podem ser mensuráveis: "Nesse sentido, o social performativo é uma parte crucial não apenas da formação do sujeito, mas também da contestação política em curso e da reformulação do assunto" (BUTLER, 1997, p. 160). O performativo promessa não é, e nem pode ser, apenas uma prática ritual, mera repetição. Seu caráter iterável traz o poder, a força, se pensarmos em termos austinianos, de (re)formar sujeitos e situações:

Dentro da esfera política, a performatividade pode funcionar precisamente nesses modelos contra-hegemônicos. Aquele momento em que um ato de fala sem autorização prévia, no entanto, assume autorização no decorrer de seu desempenho, pode antecipar e instaurar contextos alterados para sua futura recepção (BUTLER, 1997, p. 160).

\section{Prometer: uma via perigosa}

Numa visão performativa da linguagem, a promessa é perigosa. Seu risco reside em uma potência subversiva, seja ela política ou linguística. Um performativo que parte da continuidade no tempo entre o ato de comprometimento e uma ação futura, que vai se desintegrando em falhas e infelicidades, por se perder no corpo do sujeito, por não caber em um destino determinável. Ao prometer, o sujeito joga com a linguagem e levanta a possibilidade de instaurar novos sentidos, novas repartições sociais, encontrando-se ou desencontrando-se em interpelações variadas e poderosas. Daí a insurgência e o escândalo. Daí o perigo da promessa. 
Em sua pressa de definir ações e qualificar sujeitos e objetos, a promessa antecipa para o falante alguns sentidos possíveis, a partir de mundos possíveis, abrindo-se a relações entre sentidos nunca antes legitimados. Se, como afirma Rancière, a política não é feita de relações de poder, mas é feita de relações entre mundos, estou convencida de que a promessa também testemunha essa contraditória relação.

\section{Referências bibliográficas}

ALENCAR, C. Searle interpretando Austin: a retórica do "medo da morte" nos estudos da linguagem. Sínteses: revista dos cursos de pósgraduação, 2006, p. 37-47.

ALTHUSSER, L. Ideologia e aparelhos ideológicos de Estado. In: ŽIŽEK, Slavoj. Um mapa da ideologia. Rio de Janeiro: Contraponto, 1996, p. 105-142.

AUSTIN, J. L. Sense and Sensibilia. Oxford at the Claredon Press. Trad. de Armando Manuel Moura de Oliveira. Sentido e Percepção. São Paulo, Martins Fontes, 1993.

AUSTIN, J. L. How to do things with words. Oxford: Oxford University Press, 1962.

AUSTIN, J. L. Performativo-Constativo. In: Ottoni, Paulo (Org.). Visão performativa da linguagem. Campinas: Editora da Unicamp, 1998, p. 107-144.

AUSTIN, J. L. Philosophical papers. Oxford: Clarendon Press, 1961. BUTLER, J. Excitable Speech. A Politcs of the Performatives. New York: Routledge, 1997.

DERRIDA, J. A diferença. In: Margens da filosofia. Trad. de Joaquim Torres Costa e António M. Magalhães. Campinas: Papirus, 1991a, p. 33-63.

DERRIDA, J. Limited Inc. Trad. de Constança Marcondes Cesar. Campinas, SP: Papirus, 1991b.

FELMAN, S. Le scandale du corps parlant: Don Juan avec Austin ou la séduction en deux langues. Paris: Seuil, 1980.

FELMAN, S. The scandal of the speaking body: Don Juan with J. L. Austin, or seduction in two languages. Trad. de Catherine Porter. Stanford: Stanford University Press, 2003. 
GRICE, P. Meaning. The Philosophical Review 79, 1957, p. 377-388 GRICE, P. Utter's Meaning and Intention. The Philosophy Review 78, 1969, p. 147-177.

LOVE, N. Searle on language. Language \& Communication 19, 1999, 9-25

MOATI, R. Derrida/Searle: Déconstruction et langage ordinaire, Paris: Presses universitaires de France. Philosophie, 2009.

OTTONI, P. John Langshaw Austin e a visão performativa da linguagem. São Paulo. D.E.L.T.A., 18:1, 2002, p. 117-143.

OTTONI, P. Visão performativa da linguagem. Campinas: Editora UNICAMP, 1998.

PINTO, J. Algumas lições sobre o corpo. Atas do II Encontro do Grupo de Estudos Linguísticos do Centro-Oeste. Brasília, UnB, 2003, vol. II, p. 583-588.

PINTO, J. O corpo de uma teoria: marcos contemporâneos sobre os atos de fala. Cadernos Pagu [online]. 2009, n.33, p.117-138.

RAJAGOPALAN, K. On Searle [On Austin] on language. Language and Communication, 2000, p. 374-391.

RANCIÈRE, J. O desentendimento: política e filosofia. São Paulo: Editora 34, 2018.

RUBY, C. Le Champ de Bataille: post-moderne/neo-moderne. Paris: Éditions l'Harmattan, 1990.

SAUSSURE, F. Curso de Linguística Geral. 34 ed. São Paulo: Cultrix, 2012.

SEARLE, J. Intencionalidade. São Paulo: Martins Fontes, 1983.

SEARLE, J. Consciência e linguagem. São Paulo: Editora WMF Martins Fontes, 2010.

SEARLE, J. Speech acts: an essay in the philosophy of language. Cambridge, Cambridge University Press, 1969.

WITTGENSTEIN, L. Investigações Filosóficas. 6 ed. Petrópolis: Vozes, 2009.

Notas 
* Doutoranda em Linguística pela Universidade Estadual de Campinas - UNICAMP. Professora da Faculdade de Tecnologia do Estado de São Paulo - FATEC. Desenvolve pesquisas em estudos performativos e Análise de Discurso, investigando o social e o espaço urbano.

${ }^{1}$ Desenvolvido no âmbito dos estudos pragmáticos, este artigo é resultado de meu Trabalho de Qualificação de Área elaborado sob a orientação da Prof ${ }^{a}$. Dra. Joana Plaza Pinto (Universidade Federal de Goiás). A ela, deixo registrados os meus sinceros agradecimentos e estendo-os aos demais integrantes da comissão avaliadora composta pelos professores doutores Daniel do Nascimento e Silva (Universidade Federal de Santa Catarina) e Claudiana Nogueira Alencar (Universidade Estadual do Ceará).

${ }^{2}$ Os contornos contraditórios da evidente relação de sucessão de Austin por Searle são reconhecidos na obra de Rajagopalan (2000), a partir de Love (1999). O estudioso elabora explicações mais voltadas para a "sociologia do conhecimento" que para um percurso naturalizado dos estudos da Filosofia da Linguagem. Além disso, sua argumentação também está voltada para deslindar as estratégias retóricas de Searle na autoelaboração de uma posição como herdeiro intelectual de Austin.

3 Alguns autores como Ottoni (2002) e Ruby (1990) afirmam que o projeto sobre a linguagem promovido por Austin vai muito além do de Wittgenstein, sendo a primeira uma postura pós-moderna caracterizada por uma ruptura com a cultura neomoderna da qual faria parte Wittgenstein.

${ }^{4}$ Críticas presentes em suas primeiras conferências de How to do things with words e em sua obra Sense and Sensibilia, ambas publicadas originalmente em 1962.

${ }^{5}$ Nesse sentido, Searle irá distinguir entre promessa e ameaça. Uma promessa estaria ligada a fazer algo para você, não contra você; enquanto que a ameaça é uma promessa de fazer algo contra você, não para você.

6 "The meaning of a sentence does not in all cases uniquely determine what speech act is performed in a given utterance of that sentence, for a speaker may mean more than what he actually says, but it is always in principle possible for him to say exactly what he means." (SEARLE, 1962, p. 18). Tradução minha: "O significado de uma sentença não determina, em todos os casos, que o ato de fala se realiza em uma dada declaração daquela frase, pois um falante pode querer dizer mais do que o que ele efetivamente diz, mas é sempre possível, em princípio, dizer exatamente o que ele quer dizer".

${ }^{7}$ Conforme destaca Alencar (2006), o item 6.4 de SA evidencia essa ideia: "The origin of the fallacies: meaning as use".

${ }^{8} \mathrm{Na}$ obra de Derrida, différance não pode ser resumida a um nome ou um conceito essencialista, em suas palavras, différance "não é, não existe, não é um ente-presente (on), qualquer que ele seja; e seremos levados a acentuar o que ela não é, isto é, tudo; e que, portanto, ela não tem nem existência nem essência" (DERRIDA, 1991a, p. 37). Inscrita em um amplo projeto desconstrutivista cujos rumos opõem-se à ontologia da metafísica da presença, différance é condição que coloca em suspenso a determinação de presença do Ser e do Sentido e "designa a causalidade constituinte, produtora e originária, o processo de cisão e de divisão do qual os diferentes ou as diferenças seriam os produtos ou os efeitos constituídos" (DERRIDA, 1991a, p. 39). 
${ }^{9}$ No original: "In expressing that $\mathrm{p}, \mathrm{S}$ predicates a future act A of S" (SEARLE, 1969, p. 57).

10 A noção derridiana de comunicação é exposta em Assinatura Acontecimento Contexto. De um sentido veicular, de "transporte ou lugar de passagem de um sentido e de um sentido único" (DERRIDA, 1991b, p. 11, grifos do autor), a comunicação passa a ser compreendida, no caso do performativo, enquanto "comunicar uma força pelo impulso de uma marca" (p. 26). Marca-se, então, um deslocamento de um sentido metafísico para um sentido performativo de comunicação.

${ }^{11}$ De acordo com Derrida (1991b, p. 19), "essa iterabilidade (iter, derechef, viria de itara, outro em sânscrito, e tudo o que segue pode ser lido como a exploração da lógica que liga a repetição à alteridade) estrutura a marca da própria escrita, qualquer que seja, aliás, o tipo de escrita".

12 A esse respeito, os trabalhos de Pinto (2003, 2009) mencionam a IX Conferência como um marco no qual Austin ampliou suas explicações sobre atos de fala para além de questões gramaticais e fonéticas, abarcando a dimensão corporal.

13 "There is no speech act without the body, and at the same time the body limits the role of intention in the speech act" (BUTLER, 2003, p. 113).

14 "De quelle façon la loguique même de la promesse est-elle le signe d'une contradiction fondamentale, qui est celle-là même de l'humain ?" (FELMAN, 1980, p. $10)$.

15 No original : "Dire, pour lui, ce n'est en aucun cas savoir ou connaître, mais faire : agir sur l'interlocuteur, modifier la situation et ses rapports de force. Performatif et non informatif, le langage, pour lui, est un champ de joissance et non pas de connaissance ; en tant que tel, il n'est pas susceptible de vérité ou de fausseté, mais plutôt, très exactement, de bonheur ou de malheur (felicity/ infelicity), de réussite ou d'échec" (FELMAN 1980, p. 37).

16 "Utilizo, aqui, a palavra polícia e o adjetivo policial num sentido amplo, que é também um sentido 'neutro', não pejorativo. Nem por isso estou identificando a polícia àquilo que é designado pelo nome 'Aparelho de Estado'. A noção de Aparelho de Estado encontra-se de fato ligada à pressuposição de que o Estado e a sociedade se opõem [...]. Ora essa figuração já pressupõe [...] uma certa confusão entre política e a polícia. A polícia é, na sua essência, a lei geralmente implícita que define a parte, ou a ausência de parte das "partes"” (RANCIÈRE, 2018, p. 42-43). 